\title{
Using an ultrasonic generator to improve the quality of meat products
}

\author{
Sergei Shlykov ${ }^{1}$, Ruslan Omarov ${ }^{2}$, Natalya Pisarenko ${ }^{3}$, Larisa Badova ${ }^{4}$, Anatoly Pozmogov ${ }^{5}$ \\ ${ }^{1}$ Stavropol State Agrarian University, Russia, shlykovsn@gmail.com \\ ${ }^{2}$ Stavropol State Agrarian University, Russia, doooctor@yandex.ru \\ ${ }^{3}$ Stavropol State Agrarian University, Russia, akusherstvo.stgau@mail.ru \\ ${ }^{4}$ Financial University under the Government of the Russian Federation, Russia, blk2706@mail.ru \\ ${ }^{5}$ Financial University under the Government of the Russian Federation, Russia, pozmogov@bk.ru
}

\begin{abstract}
This article presents the results of the development of an algorithm for legal support of small businesses based on studying the dynamics of economic processes in this area of the economy. The main significant problems hindering the development of small and medium-sized businesses are considered. The state is a stakeholder in the development of this sector of the economy, therefore, to support it, it must develop effective and mutually beneficial programs. The analysis of the activities of small enterprises in the Republic of North Ossetia-Alania is carried out. A high share of investments by small enterprises in the total volume of regional investments in fixed assets in the country as a whole was noted, which is explained by the active participation of small businesses in housing construction and the implementation of large investment projects.
\end{abstract}

Key words : ultrasonic generator, neural networks, food systems, meat products.

\section{INTRODUCTION}

The dispersing and emulsifying ability of ultrasound is very valuable for food technology, since using this phenomenon, it is possible to obtain various homogenizates and stable emulsions with a particle size of $1 \mu \mathrm{m}$. The meat industry has a number of developments in the use of ultrasonic waves to obtain fat emulsions in sausage production [8-10]. The authors found that when a fat emulsion is added to the minced meat of frankfurters and sausages, its water-holding capacity increases and it is possible to process defrosted meat into sausages without first keeping it in the salting [1,3]. Based on the above, it was decided to determine the effect of ultrasonic waves on the qualitative characteristics of model systems with dairy protein-carbohydrate preparations, as well as to establish the possibility of using thawed meat without a curing stage in the production of meat products.

\section{MATERIALS AND METHODS}

For the manufacture of prototypes used: beef of the highest, 1 and 2 grades, low-fat pork, bacon, soy concentrate Arkon-S, bifidogenic concentrates "Lactobel" and KBU-Rs, SOM, lactose and lactulose. The preparation of minced meat was carried out in accordance with the classical scheme [2]. The amount of added moisture over the recipe was $40 \%$. Exposure of thawed meat in the salting was not carried out. The experiment was carried out according to the plan of the Greco-Latin squares.

An ultrasonic parametric generator was developed for processing model minced meat with ultrasonic waves. The block diagram of the laboratory setup is shown in Figure 1.

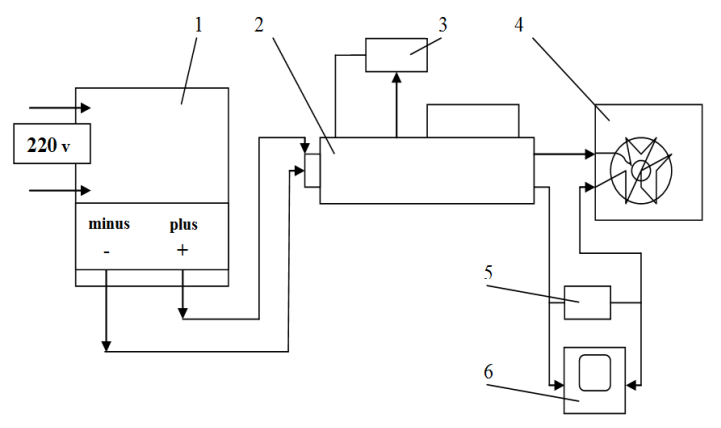

Figure 1: Block diagram of a laboratory setup of an ultrasonic parametric generator $(1$ - power supply, 2 ultrasonic generator, 3 - frequency regulator, 4 - bath with emitters, 5 - shunt, 6 - oscilloscope).

A single-phase current of industrial frequency is supplied to the power supply unit, where its output voltage is regulated in the range of $150-400 \mathrm{~V}$. After that, the required voltage is supplied to the generator for converting direct current into alternating current and adjusting to the resonant frequency. Next, one output wire is directly connected to the emitter, and the other in series with the shunt through the oscilloscope. The shunt is used to monitor the current displayed on the oscilloscope. 
Sergei Shlykov et al., International Journal of Emerging Trends in Engineering Research, 8(10), October 2020, 6903 - 6907

\section{RESULTS AND DISCUSSION}

For an effective analysis of the research results, the functional and technological properties of raw minced meat and finished products were studied (Table 1).

Table 1: Functional and technological properties of multicomponent model minced meat systems in the process of ultrasonic

(US) processing

\begin{tabular}{|c|c|c|c|c|c|}
\hline № & $\begin{array}{c}\text { Product yield, } \\
\quad \%\left(\mathrm{y}_{1}\right)\end{array}$ & $\begin{array}{c}\text { Ultimate } \\
\text { shear stress } \\
(\mathrm{PNS}), \mathrm{Pa}\left(\mathrm{y}_{2}\right)\end{array}$ & $\begin{array}{c}\text { Emulsion } \\
\text { stability, \% } \\
\left(y_{3}\right)\end{array}$ & $\begin{array}{l}\text { Moisture binding } \\
\text { ability, }\left(\mathbf{y}_{4}\right)\end{array}$ & $\begin{array}{c}\text { Penetration } \\
\text { degree, } \mathrm{mm} \\
\left(\mathrm{y}_{5}\right)\end{array}$ \\
\hline 1 & 130 & 563 & 37,5 & 81,8 & 9,7 \\
\hline 2 & 136 & 538 & 31,5 & 91,5 & 6,5 \\
\hline 3 & 136 & 515 & 26,5 & 86,2 & 5,0 \\
\hline 4 & 135 & 385 & 24,3 & 83,8 & 3,6 \\
\hline 5 & 139 & $\begin{array}{l}508 \\
\end{array}$ & 48,0 & 82,1 & 6,0 \\
\hline 6 & 135 & 495 & 25,0 & 90,1 & 8,0 \\
\hline 7 & 137 & 412 & 42,5 & 87,1 & 4,0 \\
\hline 8 & 137 & 358 & 35,0 & 85,0 & 7,6 \\
\hline 9 & 134 & 486 & 40,0 & 84,8 & 6,5 \\
\hline 10 & 134 & 450 & 23,5 & 88,7 & 7,0 \\
\hline 11 & 135 & 385 & 50,0 & 85,4 & 5,0 \\
\hline 12 & 135 & 320 & 40,0 & 86,2 & 6,0 \\
\hline 13 & 134 & 465 & 47,0 & 86,0 & 1,4 \\
\hline 14 & 132 & 423 & 49,0 & 92,9 & 7,1 \\
\hline 15 & 135 & 373 & 27,5 & 93,4 & 5,4 \\
\hline 16 & 133 & 302 & 24,0 & 86,3 & 4,2 \\
\hline 17 & 129 & 475 & 19,0 & 80,0 & 9,0 \\
\hline 18 & 124 & 523 & 11,5 & 81,3 & 6,0 \\
\hline 19 & 128 & 465 & 14,0 & 81,8 & 7,0 \\
\hline 20 & 128 & 413 & 19,0 & 81,0 & 5,0 \\
\hline 21 & 129 & 425 & 17,5 & 78,6 & 8,0 \\
\hline 22 & 125 & 456 & 11,5 & 83,2 & 8,0 \\
\hline 23 & 128 & 418 & 17,0 & 78,6 & 8,0 \\
\hline 24 & 119 & 410 & 18,5 & 80,6 & 7,0 \\
\hline 25 & 117 & 440 & 14,5 & 82,5 & 7,0 \\
\hline
\end{tabular}

To determine the optimal processing conditions, changes in the functional and technological properties of the processed and untreated ultrasound samples were revealed. The data obtained are summarized in Table 2.

Table 2: Changes in the functional and technological properties of multicomponent minced meat systems in the process of ultrasonic (US) processing

\begin{tabular}{|c|c|c|c|c|c|c|c|c|c|c|c|c|c|c|c|c|c|c|}
\hline \multirow[b]{3}{*}{ 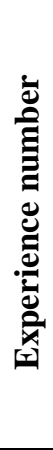 } & \multicolumn{13}{|c|}{ System components } & \multirow{2}{*}{\multicolumn{5}{|c|}{$\begin{array}{l}\text { Change in functional and technological } \\
\text { properties }\end{array}$}} \\
\hline & & & & & & ac & to tl & e ma & ss of & $\mathbf{r}$ & ieat & & & & & & & \\
\hline & 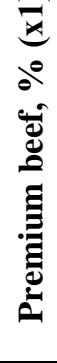 & 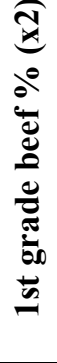 & 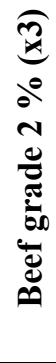 & 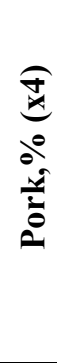 & 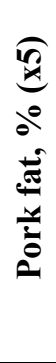 & 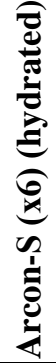 & 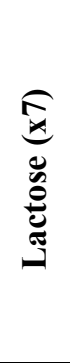 & 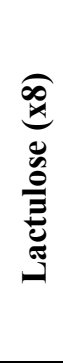 & 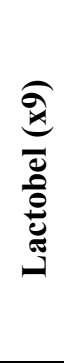 & 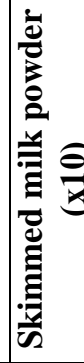 & 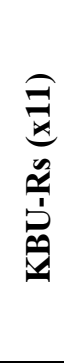 & 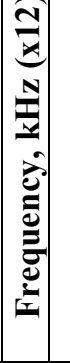 & 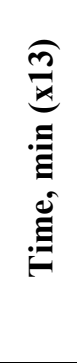 & 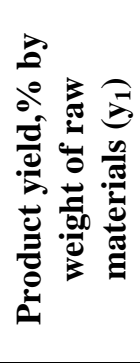 & 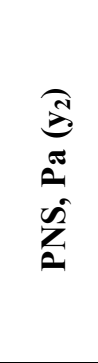 & 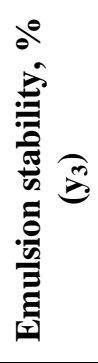 & 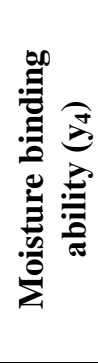 & 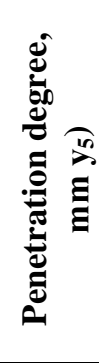 \\
\hline 1 & 25 & 25 & 25 & 25 & 0 & 0 & 0,0 & 0,0 & 0,0 & 0,0 & 0,0 & 18 & 10 & 5 & -74 & 13, & 2,7 & $-1,2$ \\
\hline 2 & 21 & 25 & 25 & 25 & 4 & 4 & 1,5 & 1,5 & 8,0 & 0,0 & 2,0 & 20 & 1 & 7 & -2 & 15 & 6 & 1,2 \\
\hline 3 & 18 & 25 & 25 & 25 & 7 & 8 & 3,0 & 3,0 & 6,0 & 0,0 & 4,0 & 23 & 1 & 9 & -1 & 10 & & $-1,1$ \\
\hline 4 & 16 & 25 & 25 & 25 & 9 & 12 & 4,5 & 4,5 & 4,0 & 0,0 & 6,0 & 30 & 10 & 7 & -76 & 7,3 & 0,8 & 3,0 \\
\hline
\end{tabular}




\begin{tabular}{|c|c|c|c|c|c|c|c|c|c|c|c|c|c|c|c|c|c|c|}
\hline 5 & 14 & 25 & 25 & 25 & 11 & 16 & 1,5 & 4,5 & 2,0 & 0,0 & 8,0 & 18 & 20 & 12 & 100 & 32,0 & 2,8 & 0,0 \\
\hline 6 & 21 & 17 & 28 & 31 & 3 & 4 & 0,0 & 3,0 & 2,0 & 2,0 & 0,0 & 20 & 20 & 9 & -15 & 11,0 & 0,1 & $-1,5$ \\
\hline 7 & 21 & 22 & 32 & 18 & 7 & 8 & 4,5 & 1,5 & 0,0 & 2,0 & 2,0 & 23 & 20 & 11 & -22 & 28,5 & 1,4 & $-1,8$ \\
\hline 8 & 22 & 26 & 19 & 22 & 11 & 12 & 3,0 & 0,0 & 8,0 & 2,0 & 4,0 & 30 & 20 & 10 & -173 & 19,0 & 1,8 & $-0,7$ \\
\hline 9 & 19 & 26 & 20 & 23 & 12 & 16 & 3,0 & 1,5 & 6,0 & 2,0 & 6,0 & 18 & 30 & 9 & -4 & 24,0 & 5,3 & $-1,8$ \\
\hline 10 & 20 & 30 & 23 & 27 & 0 & 0 & 4,5 & 0,0 & 4,0 & 2,0 & 8,0 & 20 & 30 & 7 & -51 & 7,5 & 2,1 & $-2,1$ \\
\hline 11 & 25 & 18 & 21 & 29 & 7 & 4 & 0,0 & 4,5 & 4,0 & 4,0 & 0,0 & 23 & 30 & 9 & -163 & 35,0 & 1,1 & $-2,0$ \\
\hline 12 & 22 & 19 & 22 & 28 & 9 & 12 & 1,5 & 3,0 & 2,0 & 4,0 & 2,0 & 30 & 30 & 8 & -148 & 24,0 & 1,3 & $-1,0$ \\
\hline 13 & 23 & 23 & 24 & 17 & 13 & 16 & 4,5 & 3,0 & 0,0 & 4,0 & 4,0 & 18 & 40 & 7 & 53 & 32,0 & 1,2 & 4,8 \\
\hline 14 & 24 & 28 & 31 & 17 & 0 & 0 & 3,0 & 4,5 & 8,0 & 4,0 & 6,0 & 20 & 40 & 5 & -180 & 28,0 & 5,9 & $-1,2$ \\
\hline 15 & 24 & 31 & 1 & 24 & 4 & 4 & 1,5 & 0,0 & 6,0 & 4,0 & 8,0 & 23 & 40 & 7 & -150 & 11,5 & 5,0 & $-3,3$ \\
\hline 16 & 25 & 16 & 28 & 22 & 9 & 12 & 0,0 & 1,5 & 6,0 & 6,0 & 0,0 & 30 & 40 & 6 & -191 & 8,0 & 2,2 & $-3,8$ \\
\hline
\end{tabular}

With the help of the application program neural networks, a complex neural network based on perceptrons and neurons with a radial basis function was developed (Figure 2). As a result of the analysis of experimental data by a neural network, the response surfaces of changes in each functional indicator from the frequency and time of ultrasound processing were obtained (Figures 3-7).

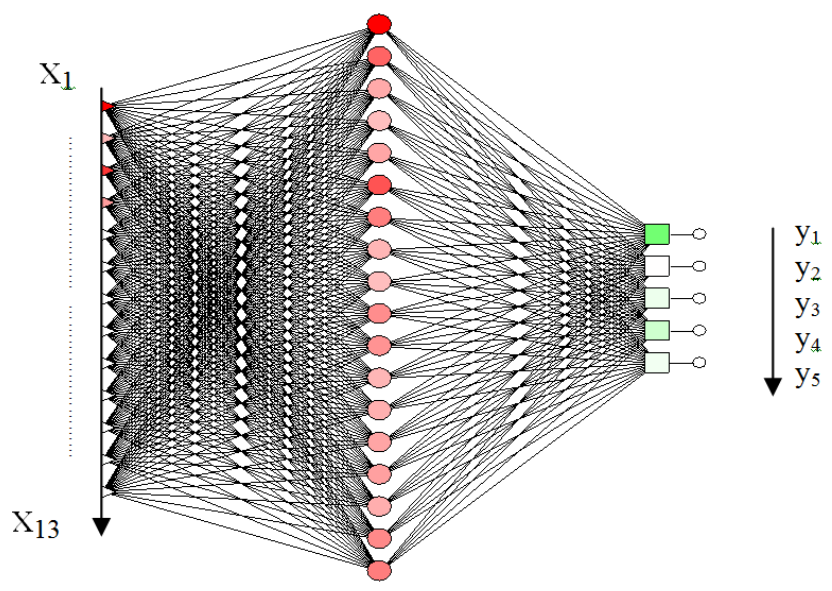

Figure 2: Neural network characterizing changes under the influence of an ultrasound field

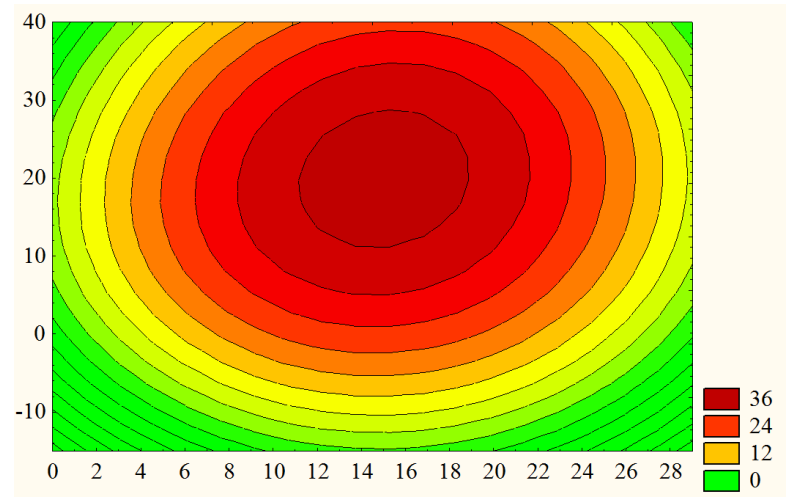

Figure 3: Influence of ultrasonic processing parameters of minced meat systems on the change in the emulsion stability index
From the response surface (Figure 3) it can be seen that the maximum difference in the stability of the emulsion is achieved at values: time from 13 to 20 minutes, at a frequency from 12 to $18 \mathrm{kHz}$. In this interval, the change in the emulsion stability index reaches $36 \%$ or more. The results obtained are consistent with the literature data, which indicate that ultrasound promotes vigorous stretching of dispersed phase droplets to unstable liquid cylinders of critical length and interferential disintegration of the resulting liquid cylinders into a number of very small droplets, i.e. mechanical destruction of fat cells and maximum dispersion of the system, which create stable emulsions with a particle size close to 1 micron $[5,11]$.

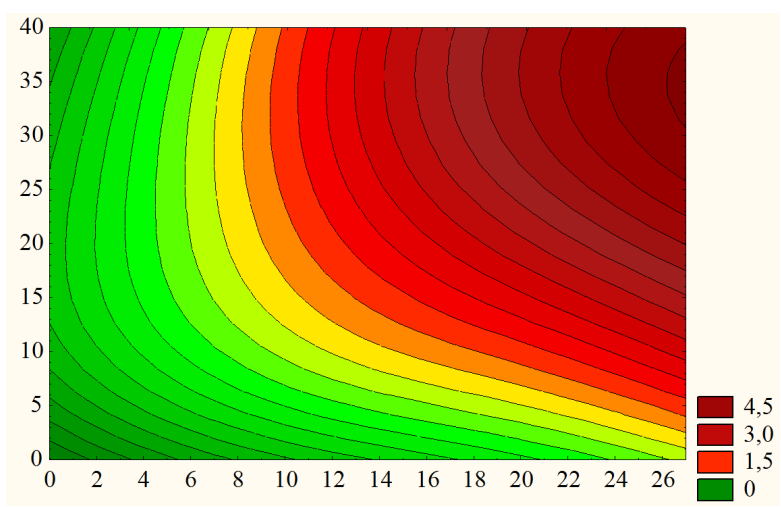

Figure 4: Influence of the parameters of ultrasonic processing of minced meat systems on the change in the indicator of water-binding capacity

When exposed to ultrasound, different parts of protein molecules are in different zones of the action of its wave. This phenomenon can lead to a change in the initial properties of protein molecules, that is, ultrasound leads to the initial stage of denaturation, accompanied by a change in the spatial structure of the protein globule, without breaking covalent bonds. Additional hydrophilic zones are formed, which leads to an increase in the VSS of the minced meat systems. 


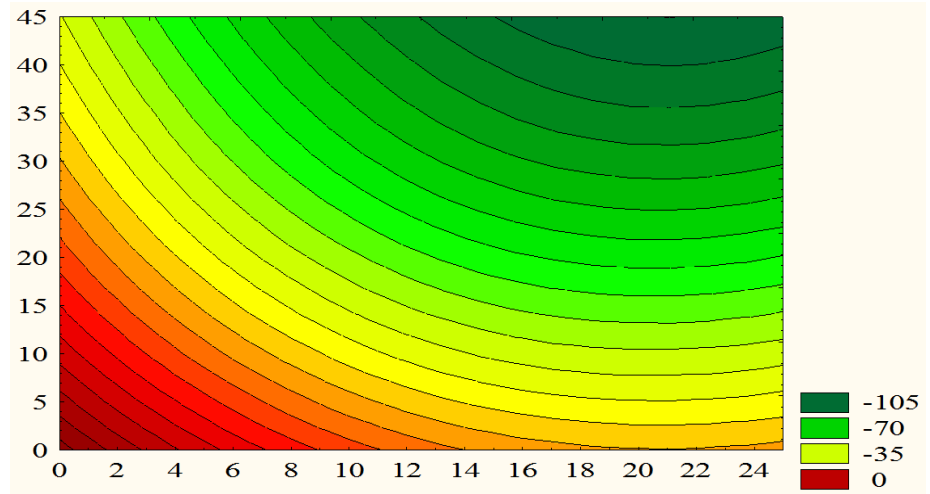

Figure 5: Influence of the parameters of ultrasonic processing of minced meat systems on the change in the index of the ultimate shear stress

Analyzing the response surface, it can be argued that an increase in the ultrasonic frequency leads to a decrease in the ultimate shear stress of minced meat systems. Under the influence of ultrasound on heterogeneous systems, the simultaneous flow of two opposite processes is observed: dispersion and coagulation. However, judging by the obtained graphical dependencies, the effect of ultrasound on the change in BCC in the protein system does not occur significant coagulation changes. In all likelihood, hydrolysis of collagen fibers of muscle tissue predominates in the optimal range, meat raw materials become more tender and soft, which is consistent with literature data $[4,6,7,12]$.

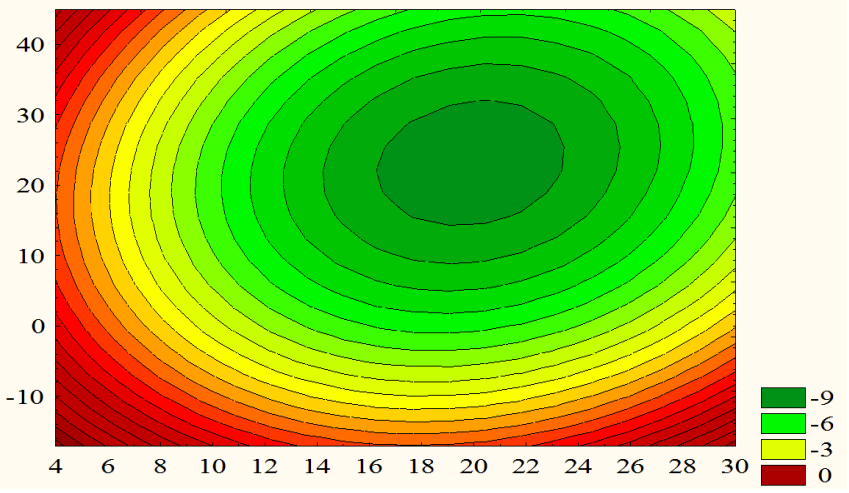

Figure 6: Influence of ultrasonic processing parameters of minced meat systems on the change in the index of the degree of penetration

The degree of penetration characterizes the density of the finished product. On the response surface shown in Figure 6, it can be determined that the maximum density is reached at times from 13 to 20 minutes at a frequency of 16 to $23 \mathrm{kHz}$. Within these limits, the degree of penetration has the greatest difference - $9 \mathrm{~mm}$. In all likelihood, heat treatment contributes to the formation of denser minced meat gels, treated with an ultrasound field due to a change in the conformation of molecules.

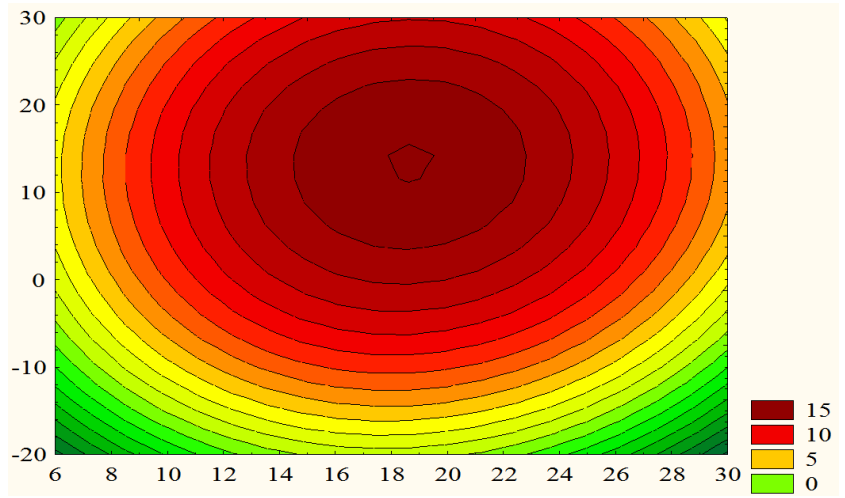

Figure 7: Influence of ultrasonic processing parameters of minced meat systems on the change in the finished product yield

The yield is an important indicator of the model minced meat; it can be seen from Figure 7 that the optimal processing parameters are the time from 16 to 19 minutes at a frequency of $18-20 \mathrm{kHz}$. In this interval, it reaches a maximum difference of $15 \%$. The output is greatly influenced by VSS and the stability of the emulsion of the minced meat system, and since an increase in these indicators is observed under the influence of ultrasound, the result is natural.

\section{CONCLUSION}

After analyzing the obtained data, the range of optimal parameters of ultrasonic processing of model minced meat was determined, which are within 15 - 19 minutes and a frequency of $18-20 \mathrm{kHz}$.

As a result of the analysis of experimental data by a neural network, graphical dependences of changes in each functional indicator on the frequency and time of ultrasonic processing were obtained. The optimal range of ultrasonic waves, providing predictable functional and technological properties, is 16-19 minutes at a frequency of $18-20 \mathrm{kHz}$. In this range, there is an increase in the water-binding capacity (from 78.6 to 93.4\%), the output of finished products (from 117 to $139 \%$ by weight of raw materials), the stability of the emulsion (from 11.5 to 50\%). A decrease in the ultimate shear stress (from 563 to 302) and the degree of penetration (from 9.7 to $1.4 \mathrm{~mm}$ ) was noted.

\section{REFERENCES}

1. A. A. Nesterenko, A. G. Koshchaev, N. N. Zabashta, R. S. Omarov, and S. N. Shlykov (2019). Basics of the production of protein-fat emulsions based on vegetable raw materials, Indo American Journal of Pharmaceutical Sciences, Vol. 6(3), pp. 6337-6346.

2. R. S.Omarov, S. N. Shlykov, A. A. Khramchenko, A. A. Gorbacheva, and A. V. Chernyavskaya (2019). Modern technological solutions in the production of 
restructured ham, Indo American Journal of Pharmaceutical Sciences, Vol. 6(3), pp. 5752-5757.

3. R. S. Omarov, S. N. Shlykov, A. A. Nesterenko, A. S. Kazakova (2019). Complex use of raw materials of animal and vegetable origin for the production of new types of desserts, Indo American Journal of Pharmaceutical Sciences, Vol. 6(3), pp. 7072-7077.

4. I. F. Gorlov, E. I. Titov, G. V. Semenov, M. I. Slozhenkina, Al. Y. Sokolov, R. S. Omarov, A. I. Goncharov, E. Y. Zlobina, E. V. Litvinova, and E. V. Karpenko (2018) Collagen from porcine skin: a method of extraction and structural properties, International Journal of Food Properties, Vol. 21:1, pp.1031-1042.

5. O. V. Sycheva, S. N. Shlykov, R. S. Omarov, and E. A. Skorbina (2019). Studying effect of electromagnetic treatment on milk technological properties, Engineering for Rural Development Proceedings, pp. 430-435.

6. O. V. Takhumova, T. I. Bondarenko, S. N. Shlykov, and Omarov R. S. (2019). Studying identification algorithms in food technology, Engineering for Rural Development Proceedings, pp. 1186-1191.

7. S. Shlykov, R. Omarov, A. Pokotilo, and A. Agarkov (2018). Muscle and marbling development in Kazakh Whiteheaded breed, Ecology, Environment and Conservation, Vol 24(1), pp. 173-176.

8. O. Takhumova, I. Danilova, T. Reusova, N. Bodryakova, and O. Bobyleva (2019). Pest-method development to assess the financial stability of logistic companies, International Journal of Engineering and Advanced Technology, Vol. 9(1), pp. 4597-4601.

9. G. K. Batov, N. I. Komkov and S. K. Shardan (2019). Prospects for Regional Development (the Case of the North Caucasian Federal District), Studies on Russian Economic Development, Vol. 30(2), pp. 205-212.

10. S. A. Tumenova, M. M. Kandrokova, S. A. Makhosheva, G. H. Batov and S. V. Galachieva (2018). Organizational knowledge and its role in ensuring competitiveness of modern socio-economic systems, Espacios, Vol. 39(26), pp. 7.

11. E. Subroto, A. D. Pangawikan, V. P. Yarlina, N. F. Isnaeni (2020). Characteristics, Purification, and the Recent Applications of Soybean Oil in Fat-Based Food Products: A Review, International Journal of Emerging Trends in Engineering Research, Vol. 8(7), pp.

3003-3011. https://doi.org/10.30534/ijeter/2020/20872020

12. A. Pozmogov, R. Omarov, S. Shlykov, L. Badova, A. Tokaeva (2020). App Development for Enterprises Financial Insolvency Diagnostic with Legal Support, International Journal of Emerging Trends in Engineering Research, Vol. 8(9), pp. 5952-5955. https://doi.org/10.30534/ijeter/2020/169892020 